\title{
Investigation of Seepage Law in Broken Coal and Rock Mass under Different Loading and Unloading Cycles
}

\author{
Zihao Kan $\mathbb{D}^{1},{ }^{1}$ Lei Zhang $\mathbb{D}^{1},{ }^{1}$ Mingxue $\mathrm{Li}^{2},{ }^{2}$ Xiaochuan Yuan, ${ }^{1}$ and Mengqian Huang ${ }^{3}$ \\ ${ }^{1}$ School of Mines, State Key Laboratory of Coal Resources and Safe Mining, China University of Mining and Technology, Xuzhou, \\ Jiangsu 221116, China \\ ${ }^{2}$ School of Materials Science and Physics, China University of Mining and Technology, Xuzhou, Jiangsu 221116, China \\ ${ }^{3}$ Shaanxi Yubei Coal Industry Xiaobaodang Mining Co. Ltd., Yulin, Shaanxi 719300, China
}

Correspondence should be addressed to Lei Zhang; leizhangcumt@163.com

Received 13 July 2021; Revised 4 August 2021; Accepted 16 August 2021; Published 1 September 2021

Academic Editor: Ondra Sracek

Copyright (C) 2021 Zihao Kan et al. This is an open access article distributed under the Creative Commons Attribution License, which permits unrestricted use, distribution, and reproduction in any medium, provided the original work is properly cited.

In order to study the seepage law of broken coal seams affected by multiple mining operations, a cyclic loading and unloading seepage experiment was carried out. For this purpose, the seepage law of broken samples with different coal and rock ratios was analyzed. The results of our study demonstrated that the permeability of the broken samples showed a decreasing trend. After a loading and unloading cycle, the permeability was significantly reduced. The impact of the loading stage on the broken sample was higher than that of the unloading phase. When the proportion of coal particles in the mixed samples of broken coal and rock was 50\%, the irreversible permeability loss rate and permeability loss rate of the samples showed the highest values. The irreversible permeability loss rate and permeability loss rate of the broken rock mass were greater than those displayed by the broken coal mass. The stress sensitivity coefficient curves of the 5 types of broken coal and rock masses presented the same changes. The stress sensitivity coefficient curve and the effective stress displayed an exponential relationship.

\section{Introduction}

As coal mining is gradually performed at deeper depths, the occurrence of coal seam groups is more frequent [1]. During the mining of deep coal seams, the mining stress path experienced by the coal seams, the evolution of the surrounding rock fissure field, and the gas seepage become complex and unstable. This makes difficult to understand the characteristics of gas migration and enrichment during repeated mining of the coal seams. The reason is that coal seam mining produces pressure release and pressurization on unmined coal seams. This causes that some coal seams repeatedly undergo loading and unloading processes during coal seam mining [2]. As effect of periodic pressure, as the working face advances the overlying rock in the goaf redistributes the stress field. This causes that the overlying rock in the goaf is always present in the pressurization zone or pressure relief zone. Under this repeated loading and unloading action, the coal seam gradually changes from a complete state to a broken state. This process changes the pore structure of the coal seam, and in consequence, the gas seepage law cannot be accurately determined. When the coal body is broken, the coal seam includes the broken coal particles. It is particularly important to study the pore structure and permeability of the broken coal rock mass that is subjected to cyclic loading and unloading processes.

Scholars have carried out research on the pore structure and seepage law of broken coal and rock mass under stress. Mccorquodale et al. [3] conducted multiple permeability tests and obtained dimensionless equations for the permeability coefficients of broken rocks with various particle sizes. Pradeepkumar et al. [4] determined that the seepage flow of broken rock obeys the Forchheimer equation and the Missbach equation. Qian et al. [5] summed up a large number of test results and concluded that, under high pressure, the permeability coefficient of broken rock masses increased an order of magnitude as compared with that of intact rock masses. In addition, the seepage of broken rock 


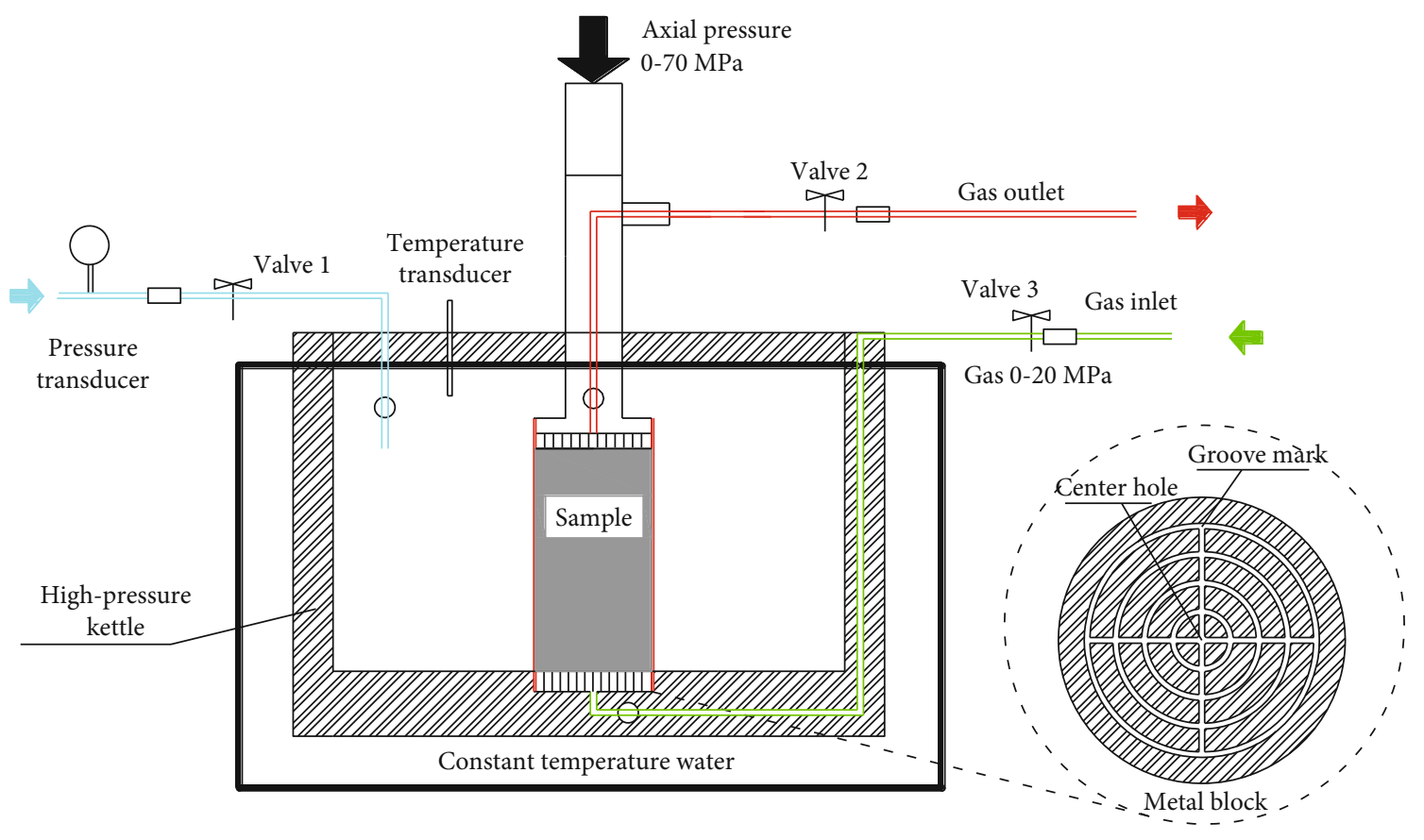

Figure 1: Gas flow and displacement testing equipment [15].

masses during in situ mining generally does not conform to Darcy's law. Shang et al. [6] obtained the porosity of broken coal samples at various particle sizes. According to their results, porosity gradually decreased with the increase of effective stress. In addition, this parameter was negatively correlated with the changing law of confining pressure. Wang et al. [7] found out that the main reason for the decrease in pore space and permeability loss of broken coal and rock samples under loading and unloading cycles is the rebreaking of coal and rock particles. According to Chu et al., the porosity and permeability of the broken coal sample gradually decreased with increasing stress. During the stress loading process, the inner physical structure of the broken coal sample changed, and the coal particles broke again. This process further affected their permeability. Yu et al. [8] determined that in the initial stage of stress loading, as porosity decreased, the permeability decreased in a linear way. Later, the permeability decreased more slowly, and finally, the permeability suddenly decreased with the decrease in porosity. Zhang et al. $[9,10]$ reported that the larger the proportion of coal in the mixed sample of broken coal and rock, the smaller the permeability, and the higher the stress sensitivity of permeability. As the number of loading and unloading cycles increased, the stress sensitivity gradually decreased. Wang et al. [11] identified that the relationship between seepage velocity and permeability and porosity can be fitted using power and exponential functions. When the porosity of a broken coal sample is high, the permeability is related to the stress loading process. When the porosity is small, the permeability tends to stabilize and does not show a relationship with the stress loading process. Zhang et al. [12] found out that the higher the proportion of large coal particles $(20-25 \mathrm{~mm})$ in the broken coal samples, the higher the permeability and stability. In addition, the larger the proportion of small coal particles $(5-10 \mathrm{~mm})$, the greater the permeability. Small coal particles presented a filling effect on large coal particles.

These researchers have also analyzed the seepage law of broken coal using data on stress effect and pore structure and compared and analyzed coal samples of different particle sizes. However, in the experimental research on broken samples, there are few researches on the broken samples mixed with coal and rock particles, and there are fewer researches on cyclic loading and unloading as the stress path. Therefore, in this paper, combining the above two aspects, five kinds of broken samples with different coal-rock ratios are made, and the permeability changes of the five kinds of samples are studied under the action of cyclic loading and unloading. The purpose of testing the permeability of broken samples is to improve the efficiency of coal seam gas drainage. The model established in the literature $[13,14]$ effectively reflects the law of gas permeability changes under fracturing.

\section{Experiments}

2.1. Laboratory Equipment. The gas flow and displacement testing equipment consisted of a loading system, autoclave, air supply and pressure reduction system, temperature simulation system, and acquisition control system, as shown in Figure 1 . The loading system is able to load the coal sample and at the same time maintain a radial pressure. The gas passes through the coal sample and enters the flow meter in order to measure permeability. The principle of the experimental device is shown in Figure 2.

2.2. Experimental Samples. The coal and rock blocks were selected from Huaibei coalfield $3_{2}$ coal seam, located in the 

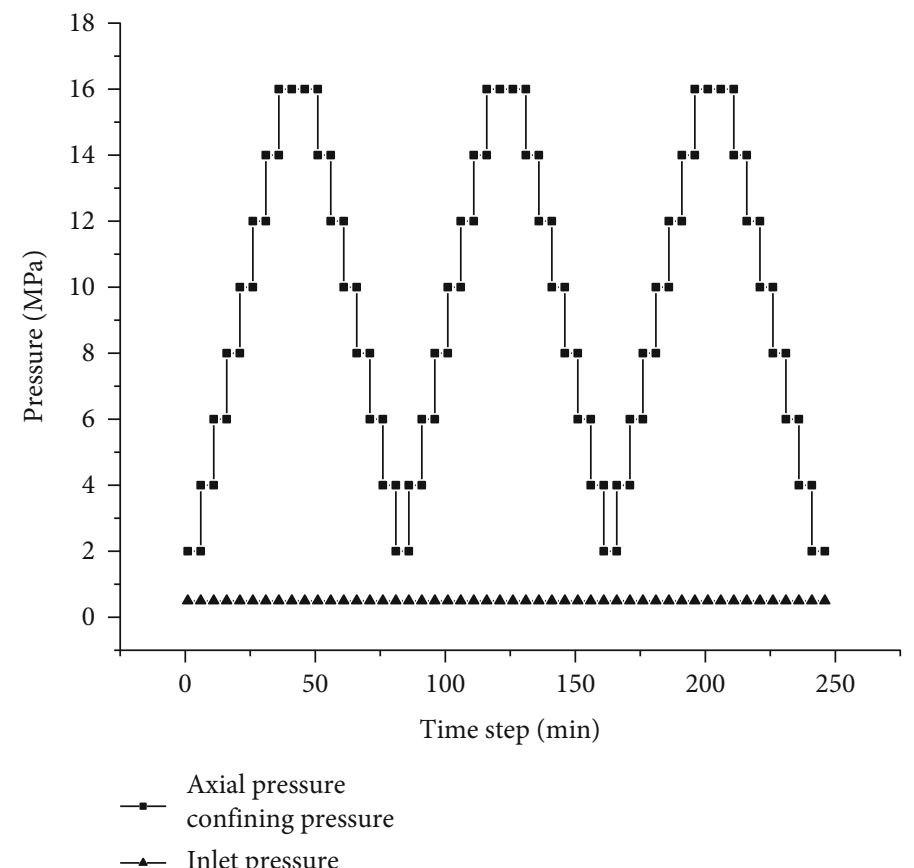

(a)

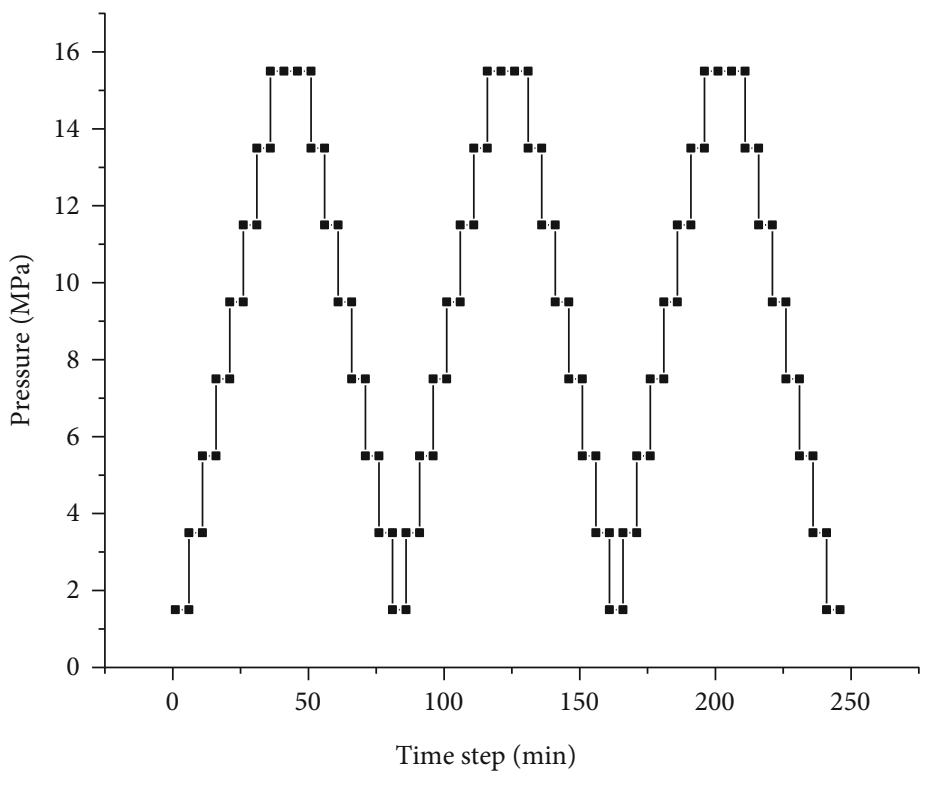

- Effective pressure

(b)

FIgURE 2: (a) Stress path and (b) effective stress path.

Anhui Province. The mine ground elevation was $+24.5 \sim$ $+25.2 \mathrm{~m}$, and the working face elevation was $-509 \sim-680 \mathrm{~m}$. The coal seams selected for these experiments corresponded to bituminous coal shown between medium and high metamorphic degrees. The rock mass was selected from the caving zone of this working face. The coal and rock blocks were ground until particles with approximately the same diameter were obtained. The diameter of the selected coal and rock particles was between 5 and $10 \mathrm{~mm}$. The coal and rock particles were mixed in order to obtain samples with a diameter of $50 \mathrm{~mm}$ and a height of $100 \mathrm{~mm}$, as shown in Table 1 and Figure 3.

2.3. Experimental Program. The cyclic loading and unloading stress path is shown in Figure 2. After the sample was placed in the experimental device, temperature was adjusted to $20^{\circ} \mathrm{C}$ and tests were performed at a constant temperature. During the loading process, the axial pressure and confining pressure were set up to $2 \mathrm{MPa}$, the inlet pressure was adjusted to $0.5 \mathrm{MPa}$, helium was charged into the 
TABLE 1: Basic data of coal samples.

\begin{tabular}{|c|c|c|c|c|c|c|}
\hline \multirow{2}{*}{ Sample } & \multirow{2}{*}{ Size $(\mathrm{mm})$} & \multirow{2}{*}{ Coal to rock volume ratio } & \multicolumn{2}{|c|}{ Volume (\%) } & \multicolumn{2}{|c|}{ Quality (g) } \\
\hline & & & Coal & Rock & Coal & Rock \\
\hline $\mathrm{C} 1$ & $50 \times 100$ & 1 & 100 & 0 & 162.1 & 0 \\
\hline $\mathrm{C} 2$ & $50 \times 100$ & 0.7 & 70 & 30 & 112.1 & 75.2 \\
\hline C3 & $50 \times 100$ & 0.5 & 50 & 50 & 83.4 & 130.1 \\
\hline $\mathrm{C} 4$ & $50 \times 100$ & 0.3 & 30 & 70 & 34.4 & 187.9 \\
\hline $\mathrm{C} 5$ & $50 \times 100$ & 0 & 0 & 100 & 0 & 263.7 \\
\hline
\end{tabular}
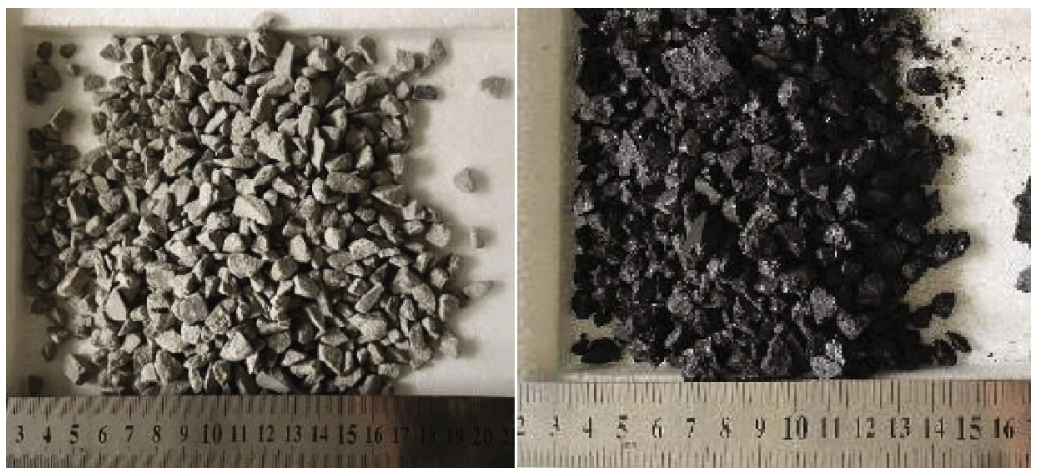

(a)
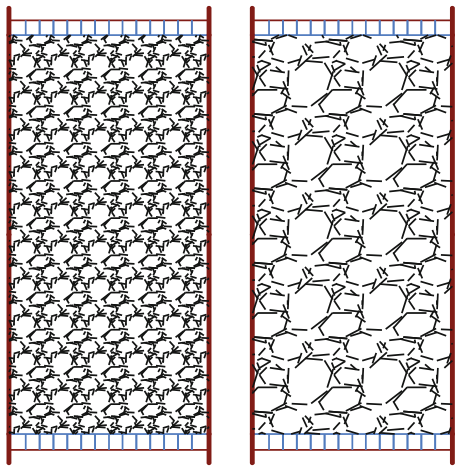

(b)

Figure 3: (a) Broken coal and rock and (b) coal samples.

experimental device, and the axial pressure and confining pressure were maintained constant for 5 minutes. The shaft confining pressure was loaded at intervals of $2 \mathrm{MPa}$ until the axial pressure and confining pressure reached $16 \mathrm{MPa}$. The unloading process started with an interval of 20 minutes after each loading. During the unloading process, the axial and confining pressures were unloaded in steps of $2 \mathrm{MPa}$, until final values were $2 \mathrm{MPa}$ and the first loading and unloading cycle and permeability test were completed [16]. Later, the same method was used to carry out the permeability test during the second and third stages of axial and confining loading and unloading processes. When the axial and confining pressures in the third stage were unloaded to reach $2 \mathrm{MPa}$, the permeability test was completed. The test for loading and unloading path and effective loading and unloading stress path is shown in Figure 2.

Equation (1) has been widely used to calculate the average effective stress in cylindrical coal samples:

$$
\sigma_{\mathrm{e}}=\sigma_{\mathrm{a}}-P,
$$

where $\sigma_{\mathrm{e}}$ is average effective stress $(\mathrm{MPa}), \sigma_{\mathrm{a}}$ is axial pressure $(\mathrm{MPa})$, and $P_{1}$ is the inlet pressure in the coal sample $(\mathrm{MPa})$.

Since coal is a porous medium, the gas flow in the coal seam can be roughly described by a linear seepage law. The formula used to calculate axial permeability of a compressible gas can be obtained by normalizing the flow rate and pressure in Darcy's theorem permeability formula:

$$
K=\frac{2 P Q \mu L}{A\left(P_{1}^{2}-P_{2}^{2}\right)},
$$

where $K$ is coal permeability (md), $Q$ corresponds to gas flow rate $\left(\mathrm{cm}^{3} / \mathrm{s}\right), \mu$ is the gas viscosity coefficient (Pa.s), $L$ indicates the coal sample length $(\mathrm{cm}), A$ is the coal sample base area $\left(\mathrm{cm}^{2}\right)$, and $P_{1}$ and $P_{2}$ correspond to the relative gas pressures at the inlet and outlet of the raw coal sample, respectively $(\mathrm{MPa})$.

In order to eliminate potential differences in pore structure caused by volume and shape variations of broken coal and rock particles, the concept of dimensionless permeability was introduced. The dimensionless permeability considers the initial permeability as the benchmark and the subsequent permeability as the benchmark and was used to express the degree of permeability change at every stress point:

$$
k=\frac{K_{n}}{K},
$$

where $k$ is the dimensionless permeability and $K_{n}$ corresponds to permeability in the subsequent stress point, excluding the first stress point (md).

\section{Experimental Results and Discussion}

3.1. Changes in Permeability of Broken Samples. According to the stress path shown in Figure 2, the loading and unloading cycles were performed to obtain five different ratios of broken coal and rock mass permeability changes. As shown in Figure 4, the permeability of broken coal and rock mass showed a decreasing trend with increasing number of loading and unloading cycles. Given the different compositions 

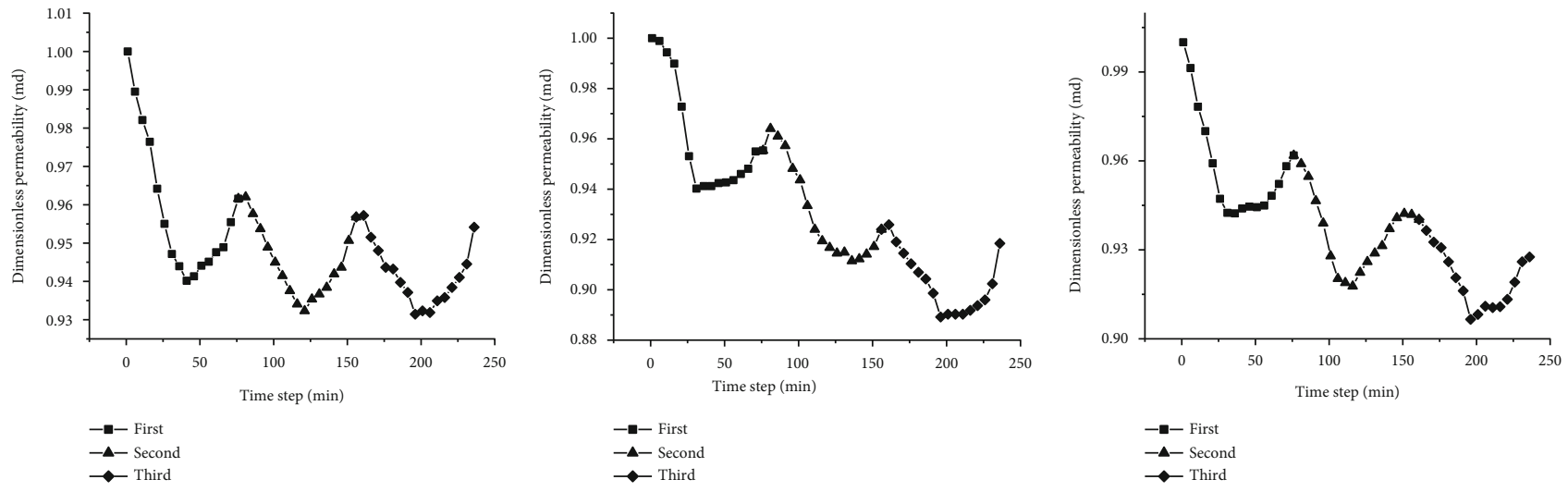

(a) $\mathrm{C} 2 / \mathrm{C} 3 / \mathrm{C} 4$ permeability curve
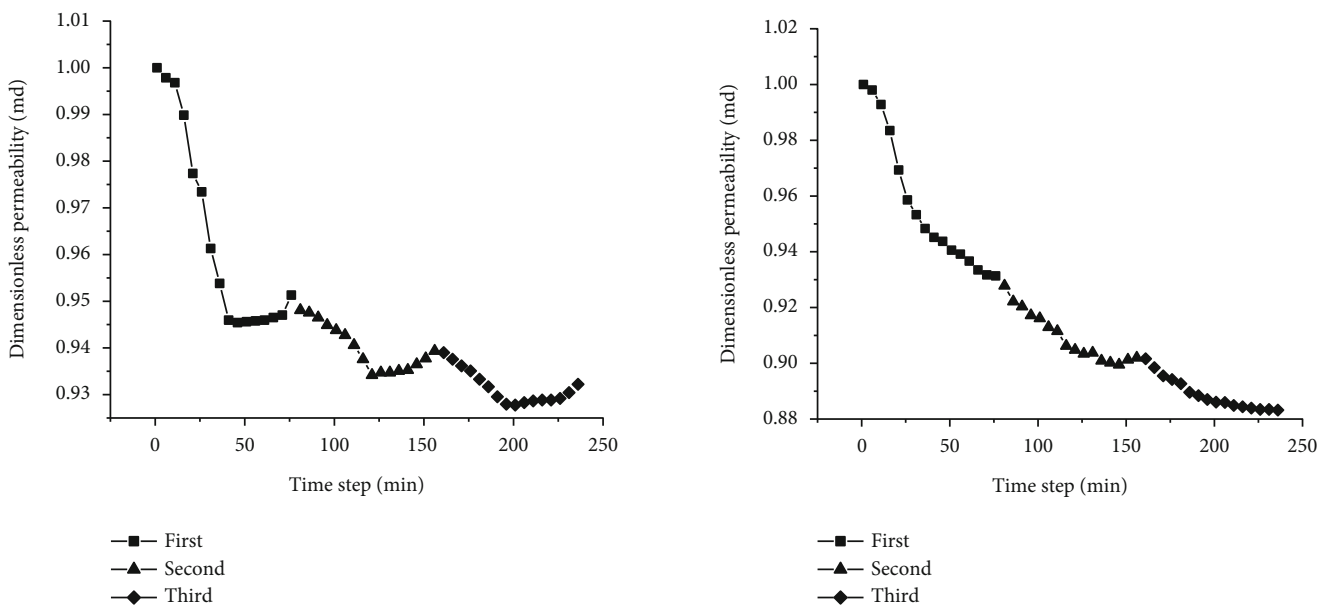

(b) $\mathrm{C} 1 / \mathrm{C} 5$ permeability curve

Figure 4: Permeability curve for samples C1/C2/C3/C4/C5.

of the five types of broken coal and rock masses, they were divided in two groups: $\mathrm{C} 1 / \mathrm{C} 5$ and $\mathrm{C} 2 / \mathrm{C} 3 / \mathrm{C} 4$. In this case, $\mathrm{C} 1 / \mathrm{C} 5$ corresponded to coal and rock samples, respectively. In addition, $\mathrm{C} 2 / 3 / 4$ indicated mixed samples. During the three loading and unloading cycles of $\mathrm{C} 2 / 3 / 4$ broken coal and rock samples, the permeability and effective stress were inversely proportional. During the loading process, the permeability of the broken coal rock decreased and later increased during the unloading stage. Data indicated that stress during loading and unloading stages presented two maximum points. In addition, the permeability curve displayed three minimum points. Permeability of $\mathrm{C} 2 / 3 / 4$ decreased as the number of loading and unloading cycles increased. It was also observed that the damage to the broken coal and rock mass gradually increased after three loading and unloading cycles. During the cyclic loading and unloading of $\mathrm{C} 1$ crushed coal, the overall change was the same as the one observed in C2/3/4. In addition, the change range of the extreme point inside the permeability curve was small, even smaller than the one observed in the $\mathrm{C} 2 / 3 / 4$ sample. The permeability of $\mathrm{C} 5$ broken rock mass always decreased, and no extreme point was present. These results differed from those obtained for $\mathrm{C} 1$ fractured coal mass. During cyclic loading and unloading processes of the
TABLE 2: Permeability variation.

\begin{tabular}{lccccc}
\hline Sample & C1 & C2 & C3 & C4 & C5 \\
\hline Loading 1 & 0.046 & 0.056 & 0.059 & 0.058 & 0.052 \\
Unloading 2 & -0.005 & -0.021 & -0.014 & -0.018 & 0.014 \\
Loading 2 & 0.011 & 0.028 & 0.045 & 0.041 & 0.022 \\
Unloading 2 & -0.005 & -0.024 & -0.007 & -0.020 & 0.003 \\
Loading 3 & 0.011 & 0.026 & 0.037 & 0.034 & 0.015 \\
Unloading 3 & -0.004 & -0.022 & -0.028 & -0.019 & 0.003 \\
\hline
\end{tabular}

broken coal and rock mass, the particles resulted from three different processes: extrusion deformation, particle crushing, and structural adjustment; the permeability changes of $\mathrm{C} 1 / 2 / 3 / 4 / 5$ at each stage are shown in Table 2 . When coal and rocks were mixed, for example, in $\mathrm{C} 2 / 3 / 4$, particle crushing and extrusion deformation represented the main factors. On the other hand, in broken coal and rock samples mixtures (i.e., C1/5), structural adjustment and extrusion deformation represented the main processes. The specific shape is shown in Figure 5.

In order to further illustrate potential changes in permeability of broken coal and rock mass subjected to three 


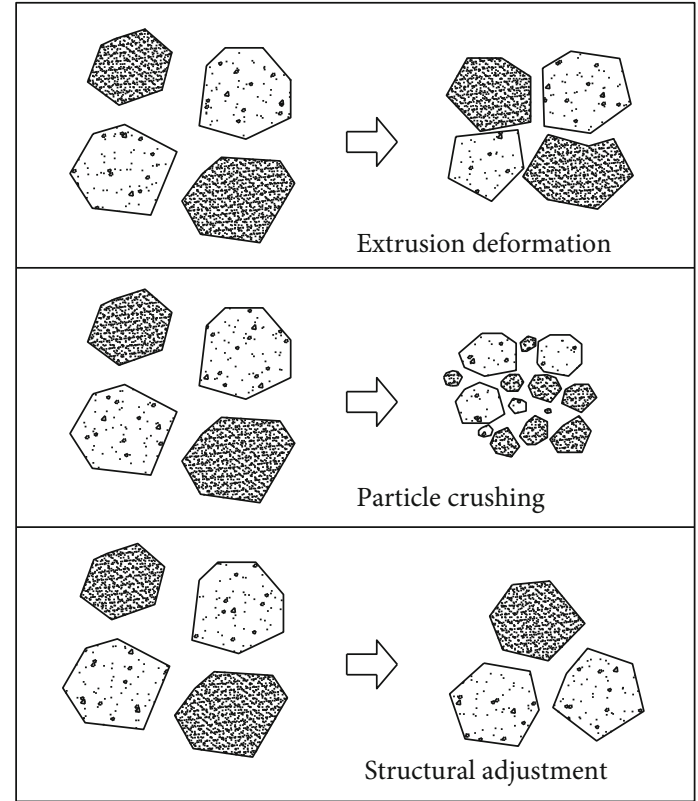

Figure 5: Three different processes occurring during loading and unloading of broken coal and rock mass samples.

loading and unloading cycles, the deformation of the granular particles was calculated using the Hertz contact deformation principle [17]. Before loading and unloading of the broken coal and rock mass, multiple particles presented high porosity. Herein, particle size and volume of the fracture channel present inside the sample were large. At this point, permeability presented the highest value. It was observed that, at high values of effective stress, no cohesion between the particles occurred, and the multiparticle pore structure started breaking down. At this time, the area of the pore seepage channel was greatly reduced. As stress further increased, a relatively stable pore structure was eventually formed. At the same time, because of the low strength and irregular shape of broken coal and rocks, samples were again broken during the loading and unloading cycle (Figure 5). The diameter of broken particles after loading and unloading cycles was significantly smaller than that of large particles. Also, the fracture channels composed of tiny particles were smaller than those composed of large particles. In addition, some small broken particles were able to fill the pore space of large particles, and at the same time, the particle structure was again adjusted [18], as shown in Figure 6. The pore structure of broken coal rocks was not restored during the unloading stage. This process produced a significant loss of permeability of the broken coal rock sample during the first loading and unloading process. In subsequent loading and unloading cycles, the coal and rock samples were broken again to a much lower degree as compared to the first loading process, and the structure between the particles was relatively stable [19]. Therefore, the permeability of the broken coal and rock samples during the secondary and tertiary loading and unloading processes decreased to a small extent. In addition to the irreversible permeation loss that resulted from changes of the pore structure of the broken coal samples and recrushing, the squeezing deformation

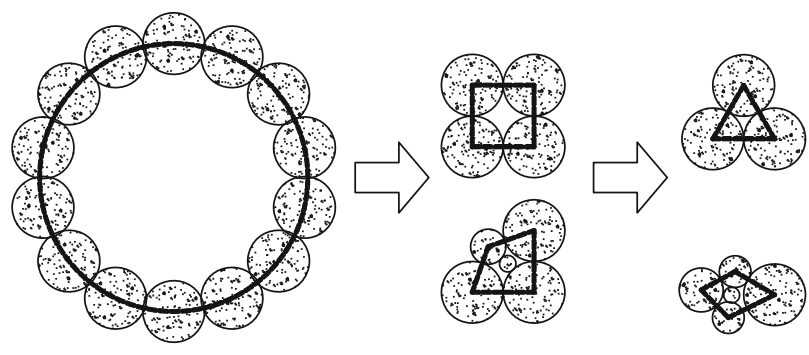

FIgURE 6: Changes in pore structure of broken coal and rock mass.

of the broken particles during the formation of the pore structure was also the reason for the reduction of porosity.

In order to determine the cause for the continuous decrease in permeability of broken coal and rock masses during the cyclic loading and unloading processes [20], the concept of the cubic law was introduced. Different researchers have [21] studied the seepage mechanism of water in rough fractures and have proposed use of the cubic law. The formula is presented in

$$
Q=\frac{e^{3}}{12 \mu} \frac{P_{2}-P_{1}}{\mathrm{JC}^{0.03}}
$$

where $Q$ represents the flow through the pipeline $\left(\mathrm{m}^{3} / \mathrm{s}\right), e$ is the crack opening $(\mathrm{m}), \mu$ corresponds to the fluid viscosity coefficient, JRC is the roughness coefficient, and $P_{2}-P_{1}$ is the pressure difference between adjacent fluid domains $(\mathrm{MPa})$, and a positive value indicates that the direction of flow velocity occurs from fluid domain 2 to fluid domain 1 .

Different researchers [22] have used the root mean square $Z$ of the structural surface to estimate the roughness coefficient JRC and have obtained

$$
\mathrm{JRC}=32.2+32.47 \lg Z .
$$

The root mean square $Z$ formula of the surface profile is shown in

$$
Z=\frac{1}{L} \sqrt{\int_{x=0}^{x=L}\left(\frac{d y}{d x}\right)^{2} d x},
$$

where $L$ corresponds to the length of the pipe $(\mathrm{m})$. As shown in Figure 7, $L=r_{1}+r_{2}$.

During the experiments, the broken coal and rock mass underwent three processes including deformation, particle crushing, and structural adjustment. The initial particle size was relatively large. After loading and unloading cycles, the coal and rock mass broke again and the particle size was reduced. The width of the cracks between them was reduced, as well as the length of the cracked pipes. According to Equation (4), $L$ decreased and the root mean square $Z_{2}$ of the surface profile increased. In addition, as shown in Equation (3), in general, JRC increased. Furthermore, according to Equation (2), the flow rate of crushed coal and rock mass decreased, and coal was compressed. The permeability of the coal and rock mass decreased accordingly. Thus, the permeability of the broken coal rock always 


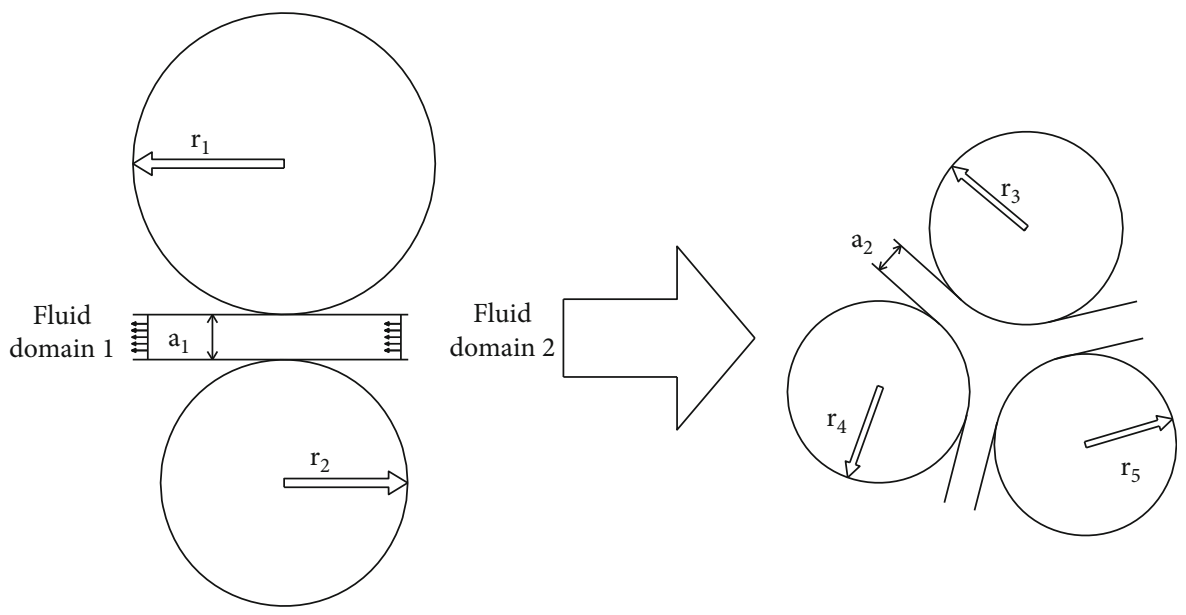

FIGURE 7: Seepage channel changes in broken coal and rock mass during loading and unloading processes.
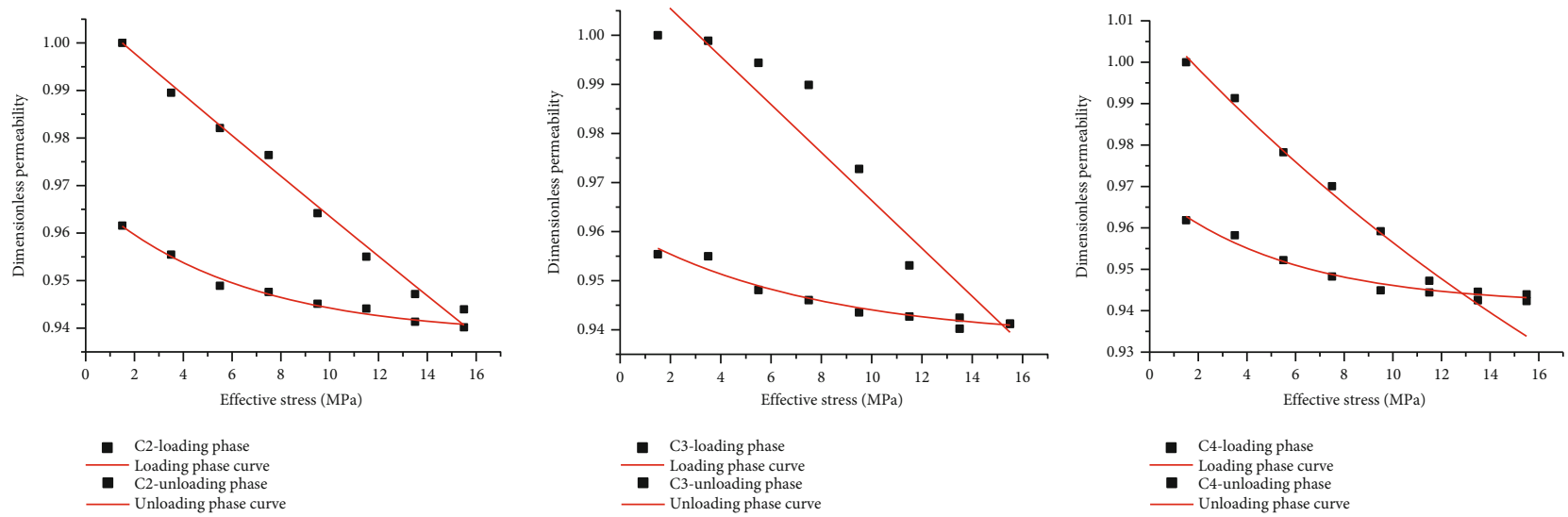

(a) $\mathrm{C} 2 / 3 / 4$ coal sample
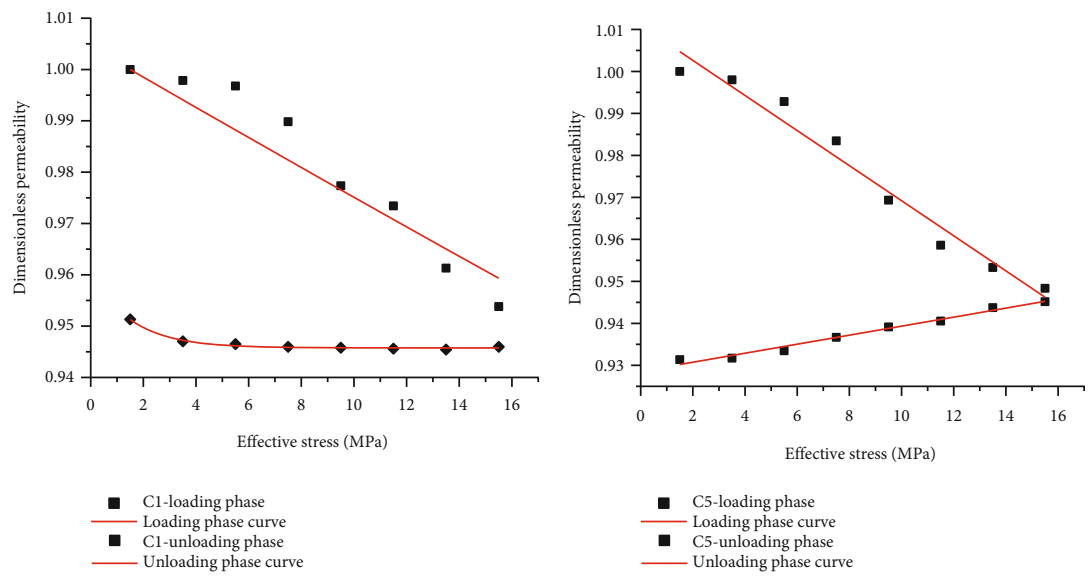

(b) $\mathrm{C} 1 / 5$ coal sample

Figure 8: Permeability curve for the first loading and unloading cycle.

showed a decreasing trend during the loading and unloading cycles.

According to our results, significant changes in permeability were observed when broken coal rock masses C1/2/3/4/5 passed through one loading and unloading cycle. Figures 8 and 9 show the permeability curves for 5 different types of broken coal rock masses with effective stress as the independent variable. Figure 8 shows data obtained in the first cycle. In addition, Figure 9 presents the permeability of the samples during the second and third loading and unloading cycles. Data indicated that, throughout the loading stage, the highest slope of the permeability curve corresponded to the C3 sample, followed by that of C4 and C2. At the beginning of the first loading step, small differences 

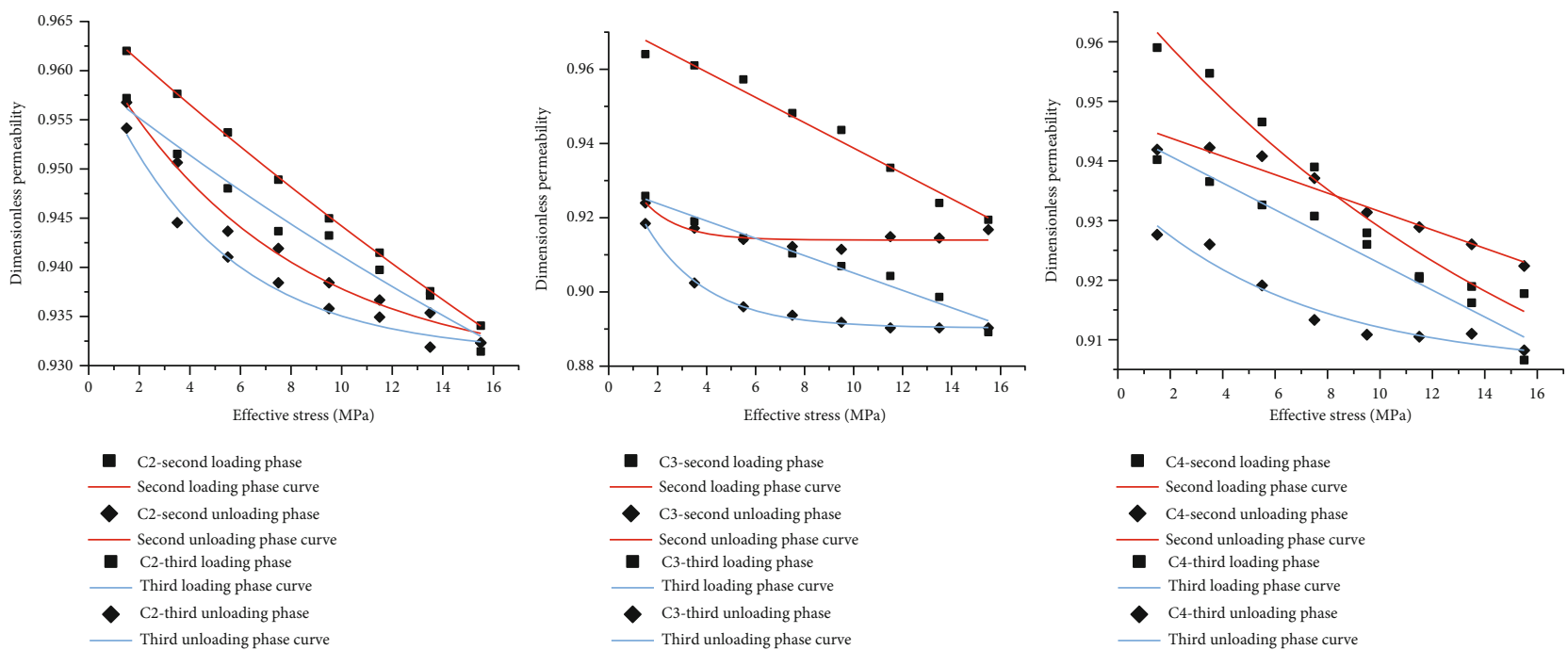

(a) $\mathrm{C} 2 / 3 / 4$ coal sample
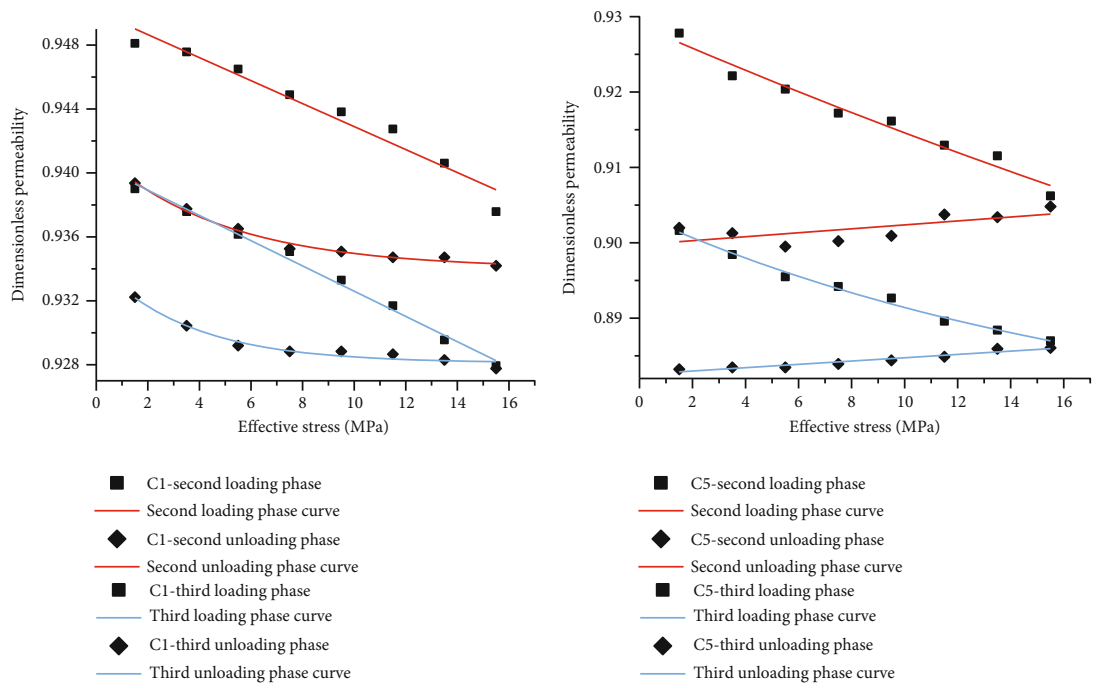

(b) $\mathrm{C} 1 / 5$ coal sample

Figure 9: Permeability curves for the second and third loading and unloading cycles.

in permeability were observed in the three samples. However, as effective stress increased, the permeability of the C3 sample decreased, and the slope increased. This occurred because the $n$ value for the samples C2, C3, and C4 was 0.7 , 0.5 , and 0.3 , respectively. Thus, the volume of coal and rock particles in the sample accounted for $70 \%, 50 \%$, and $30 \%$. During the loading process, the internal particles were mainly ground by extrusion. Since the hardness of the rock was higher than that of the coal, the internal coal particles were fractured again during the loading process. These particles filled the internal cracks of the rock. When the proportion of coal particles was $30 \%$, the volume of the internal fissures present in the rock particles was larger, the filling volume of the coal particles was smaller, and the structural change of the pores was smaller than the ones observed in samples containing a coal ratio of $50 \%$. When the proportion of coal particles was 70\%, the coal particles in contact with the rock units were broken through particle crushing. On the other hand, when coal particles were not in contact

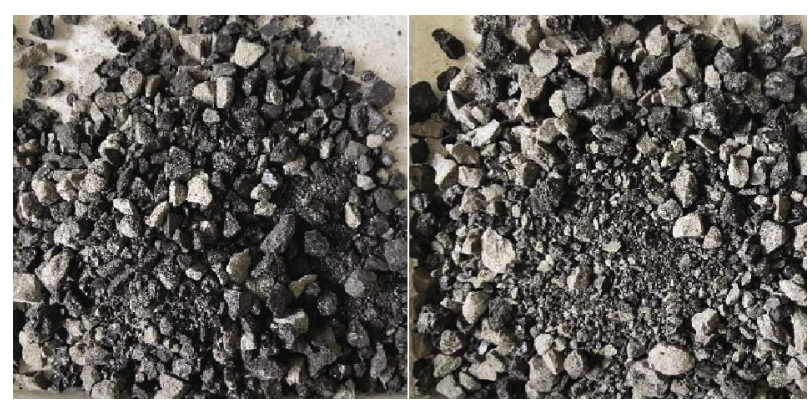

FIgURE 10: C2 and C3 samples after loading and unloading cycle.

with the rock particles, fragmentation was mainly due to extrusion, deformation, and structural adjustment. Moreover, when the proportion of particles was $50 \%$, the coal and rocks were fully mixed and in full contact. For this reason, coal particles were fragmented again after being squeezed [23]. Figure 10 shows that, after three loading 


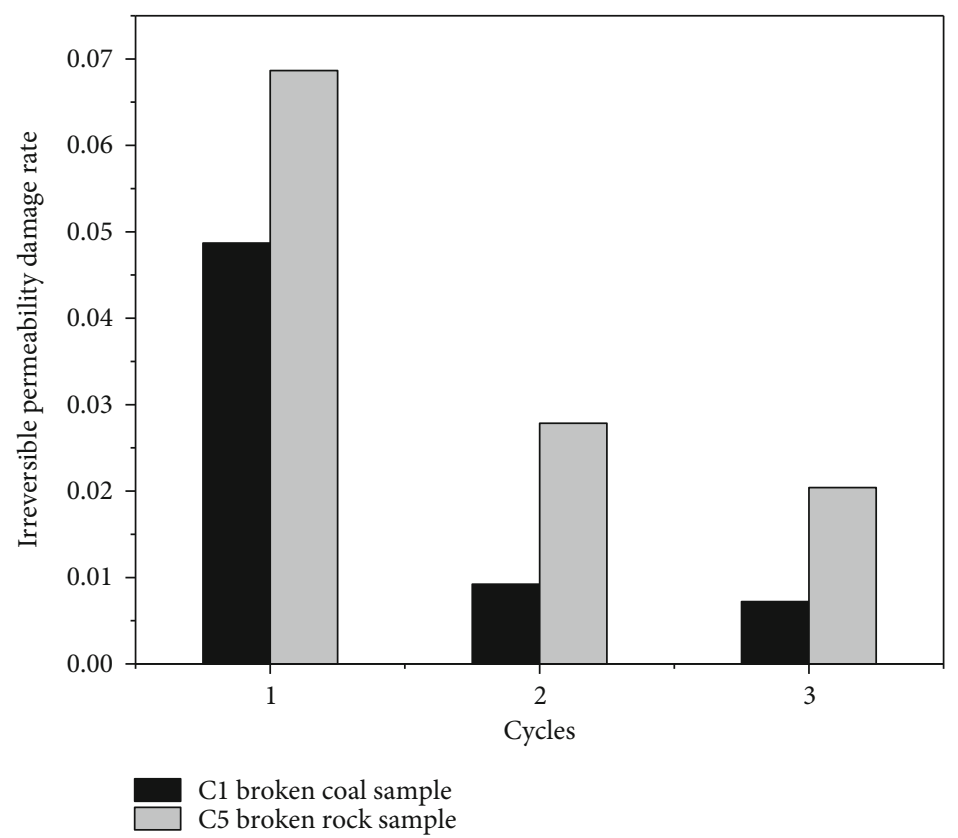

(a) $\mathrm{C} 1 / 5$

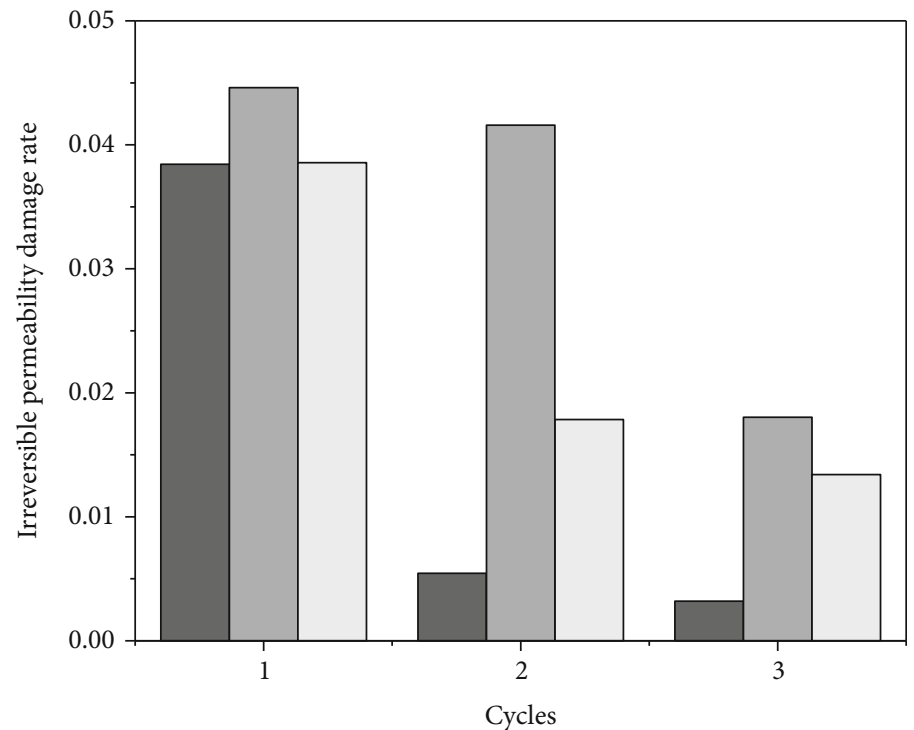

$\mathrm{C} 2 n=0.7$

$\mathrm{C} 3 n=0.5$

$\mathrm{C} 4 n=0.3$

(b) $\mathrm{C} 2 / 3 / 4$

Figure 11: Irreversible permeability loss rate of $\mathrm{C} 1 \sim 5$ during three loading and unloading cycles.

and unloading cycles, the degree of fragmentation in the C3 sample was greater than that observed in the C2 sample. When the coal-to-rock ratio was 0.5, significant deformation of the broken coal and rock was observed, and the pore structure was notably damaged.

3.2. Permeability Damage Rate. In order to explore the influence of cyclic loading and unloading processes on the permeability of broken coal and rocks, the concept of irreversible permeability damage rate was introduced. The irreversible permeability damage rate represents the change in the perme- ability of the broken sample during the cyclic loading and unloading process, considering that this change is irreversible. The irreversible permeability damage rate (\%) is expressed as shown in Equation (7) and indicates to which degree the permeability of the coal reservoir cannot be recovered [24]:

$$
D_{k_{1}}=\frac{k_{1}-k_{1 r}}{k_{1}} \cdot 100 \%
$$

where $D_{k_{1}}$ corresponds to the irreversible permeability damage rate after stress is returned to the first stress point, $k_{1}$ 


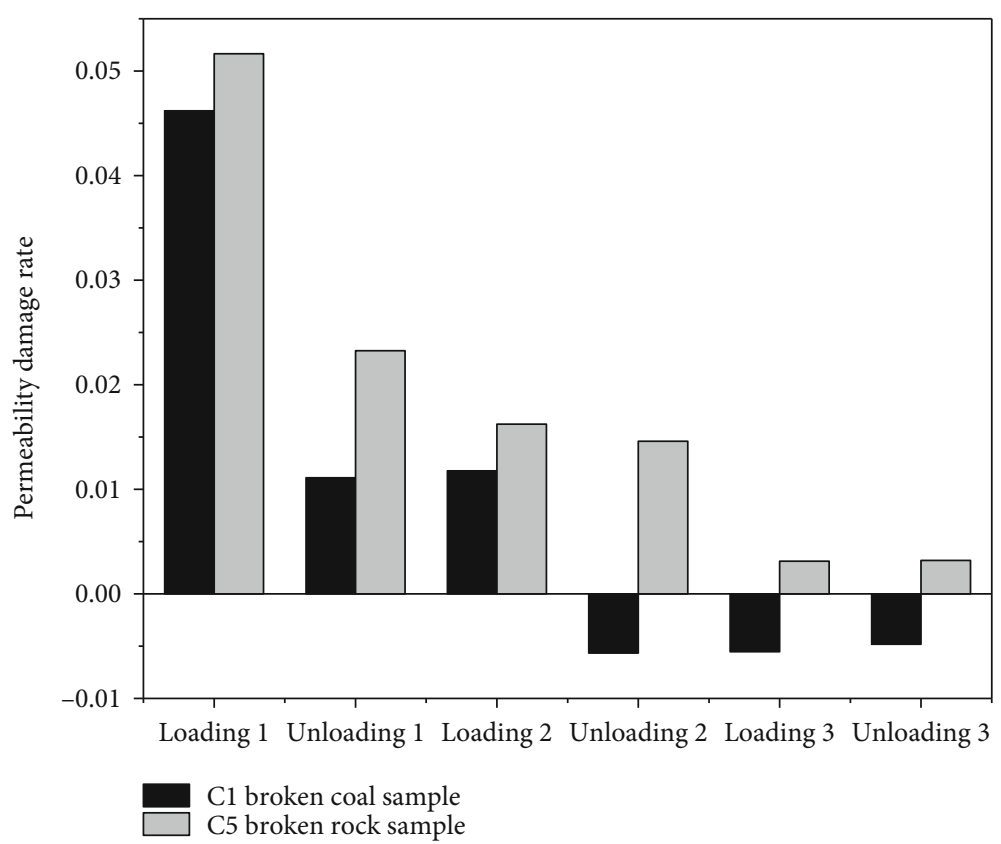

(a) $\mathrm{C} 1 / 5$

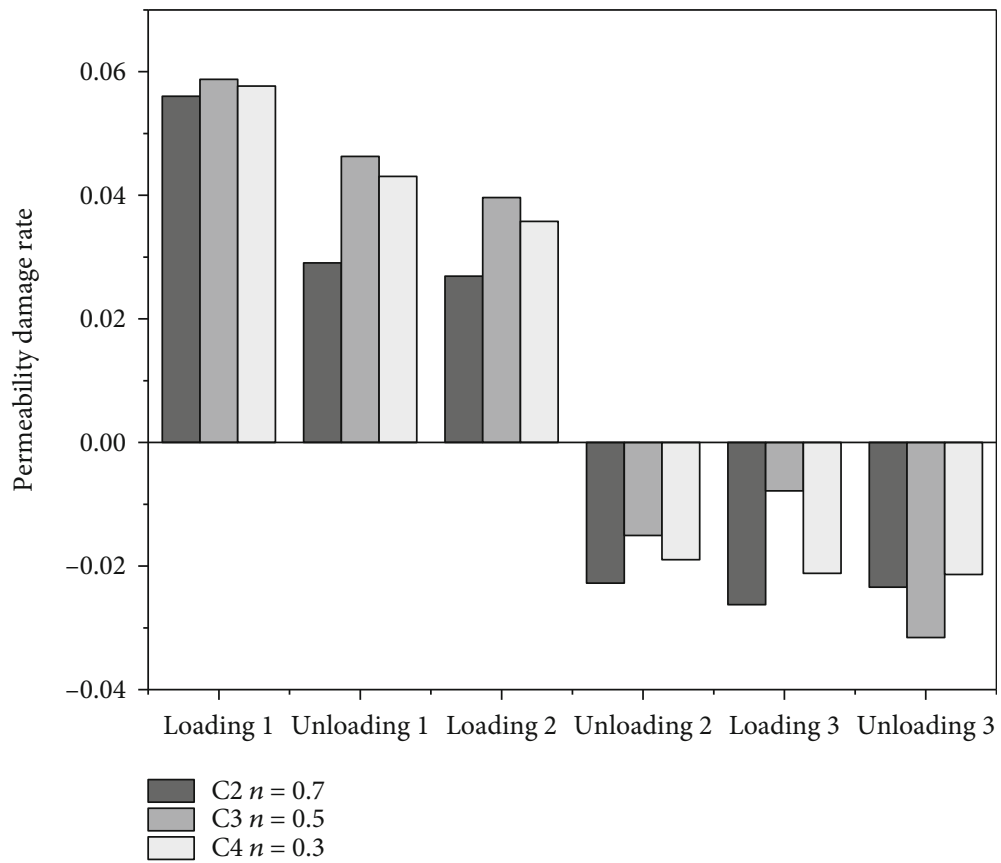

(b) $\mathrm{C} 2 / 3 / 4$

FiguRE 12: Rate of permeability loss in samples C1 5 under three loading and unloading cycles.

indicates the permeability at the first stress point (md), and $k_{1 r}$ is the permeability after the stress returns to the first stress point (md).

According to the data shown in Figure 11, the irreversible loss rate of the five broken samples gradually decreased when the number of loading and unloading cycles increased. Results for samples $\mathrm{C} 1$ and C5 indicated that, during the three loading and unloading cycles, the irreversible damage rate of the broken rock sample was higher than that of the broken coal sample. The coal used for the broken sample was taken from the $3_{2}$ coal seam of the Huaibei Coal Field. This coal seam corresponds to an outburst coal seam. Therefore, the coal sample displayed a plastic change relative to the rock sample during the cyclic loading and unloading process. The compression deformation during the loading and unloading process caused that the ratio of the broken rock was higher than that of the coal. In $\mathrm{C} 2 / 3 / 4$, which corresponds to three different types of crushed mixed samples, the irreversible damage rate after three loading and unloading cycles followed the order $\mathrm{C} 3>\mathrm{C} 4>\mathrm{C} 2$. When the coal- 

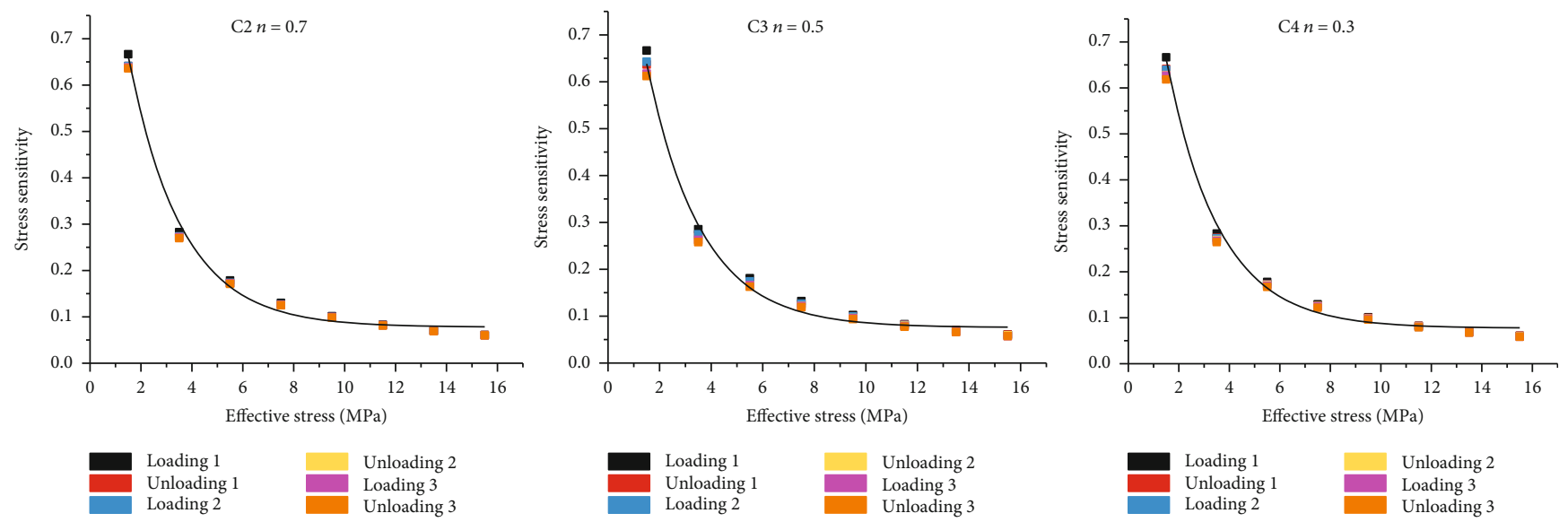

(a) Stress sensitivity curve for samples C2/3/4
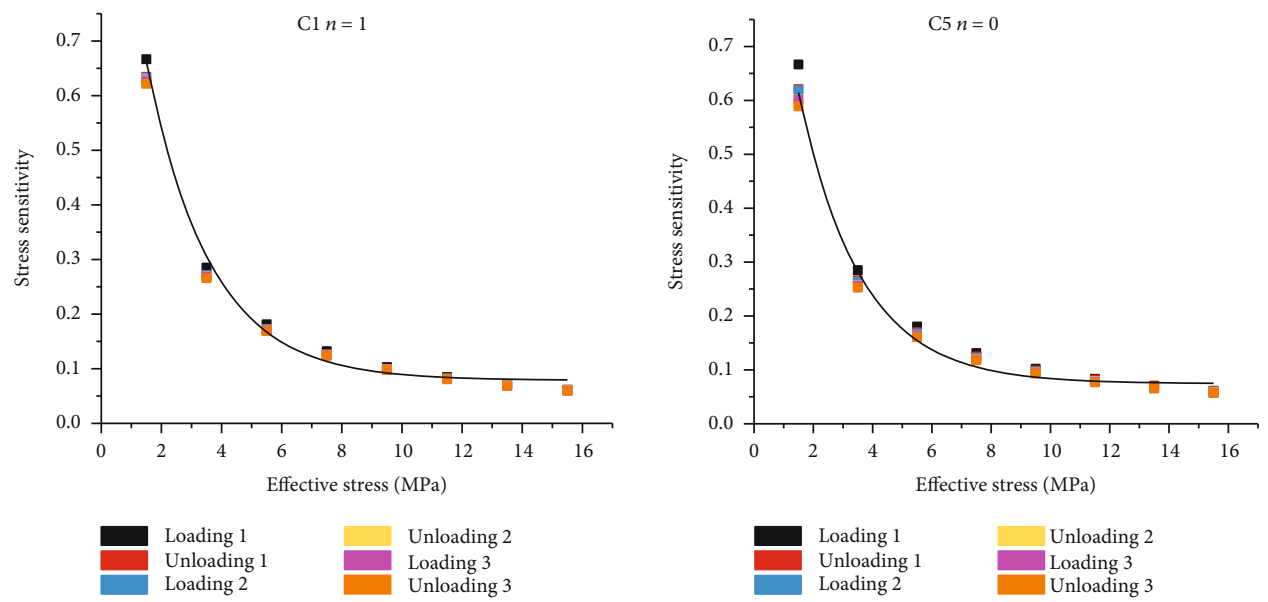

(b) Stress sensitivity curve for samples $\mathrm{C} 1 / 5$

FIgURE 13: Stress sensitivity curve for samples C1 to C5.

to-rock ratio was 0.5 , the coal-rock was fully mixed and the refragmentation of the internal particles resulted in a large difference in permeability of C3 crushed coal and rock, as well as a high irreversible damage rate. For C2 and C4 samples, differences in the irreversible damage rate between the first loading and unloading cycle were small. In addition, this difference increased as the number of loading and unloading cycles increased. The irreversible permeability of the $\mathrm{C} 4$ sample was greater than that of $\mathrm{C} 2$. In broken coal and rocks, when the proportion of rock particles was relatively large, the degree of damage in the internal particles and the degree of pore structural change increased. Moreover, when the proportion of coal and rock was the same, the degree of change presented the highest value.

In order to determine the impact of the test on each section of the broken coal and rock mass during loading and unloading processes, the concept of permeability damage rate (\%) was introduced, and it is shown in [25]

$$
D_{k_{2}}=\frac{k_{1}-k_{2}}{k_{1}} \cdot 100 \% \text {, }
$$

where $D_{k_{2}}$ represents the permeability damage rate at a certain loading and unloading stage, $k_{1}$ is the permeability corresponding to a stress point at the beginning of a given loading or unloading stage (md), and $k_{2}$ indicates the permeability corresponding to a stress point at the end of a given loading or unloading stage (md).

Figure 12 shows that the permeability damage rate of the five types of broken coal and rock masses gradually decreased during the loading stage. In the case of $\mathrm{C} 1 / 5$, the permeability damage rate of the broken rock sample was greater than that of the broken coal sample. In addition, when performing the three loadings of the $\mathrm{C} 2 / 3 / 4$ broken mixtures, it was observed that the permeability damage rate of the $\mathrm{C} 3$ broken sample was greater than that of the $\mathrm{C} 2 / 4$ broken samples. The permeability damage rate of the $\mathrm{C} 4$ broken sample with a proportion of coal particles of 0.3 was greater than that of $\mathrm{C} 2$. The internal particle change law and the permeability differences were in agreement. In the unloading stage, the permeability damage rate of C5 fractured rocks was all greater than " 0 ," and the permeability damage rate of samples containing coal particles was less than "0." This occurred because of the inverse relationship between permeability and effective stress. In relation to C2/3/4 crushed mixed samples, the permeability damage rate of $\mathrm{C} 3$ was smaller than that of $\mathrm{C} 2 / 4$. It was also observed 


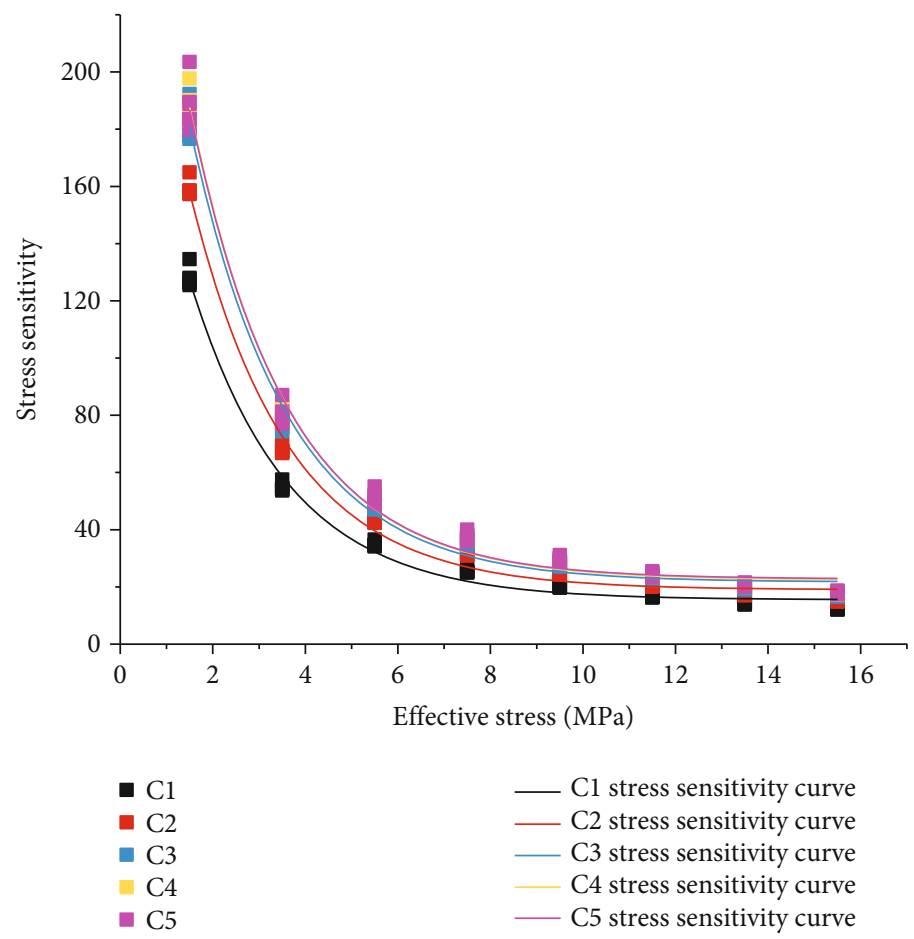

FIGURE 14: Comparison of sensitivity curves of five broken samples.

that, in the third unloading stage, the penetration damage rate of $\mathrm{C} 3$ was greater than the one observed in $\mathrm{C} 2 / 4$ broken samples.

3.3. Stress Sensitivity Analysis. In order to quantify the sensitivity of permeability to stress changes under cyclic loading and unloading conditions, the stress sensitivity coefficient $C_{k}$ of permeability was determined using

$$
C_{k}=\left|\frac{\partial k}{\partial \sigma_{\mathrm{e}}}\right|,
$$

where $K$ represents the permeability of the coal sample (md) and $\sigma_{\mathrm{e}}$ is the effective stress $(\mathrm{MPa})$.

In order to perform the analysis, permeability data for samples $\mathrm{C} 1 \sim 5$ were loaded into the formula, and the relationship between stress sensitivity and effective stress of broken coal sample permeability under cyclic loading and unloading conditions was calculated. Results are shown in Figure 13.

Data shown in Figure 13 indicated that the stress sensitivity of the permeability of the broken coal and rock mass in the cyclic loading and unloading process gradually decreased with the increase of the effective stress. It was also observed that, regardless of the stage, the stress sensitivity of permeability in broken coal samples gradually decreased with the increase in the number of loading and unloading cycles. The stress sensitivity of coal sample permeability at the loading stage was greater than the stress sensitivity in the corresponding unloading step. From the first loading and unloading to the third loading and unloading cycles, the stress sensitivity coefficient of the broken coal and rock mass gradually decreased.
Figure 14 presents a comparison of the stress sensitivity of the five broken samples. The ordinate in Figure 14 is different from that in Figure 13. The ordinate corresponds to the stress sensitivity resulting from the real permeability of the broken coal sample. As this figure shows, the highest point in the stress sensitivity curve gradually increased as samples went from $\mathrm{C} 1$ to $\mathrm{C} 5$, which is related to the initial permeability of the broken sample when the effective stress was $1.5 \mathrm{MPa}$. The higher the initial permeability, the initial stress sensitivity coefficient increased. In addition, the range of stress sensitivity variation for samples C1 5 gradually increased. The higher the amount of rock particles inside the broken sample, the higher the sensitivity of the sample to the effective stress and the greater the degree of change.

\section{Conclusion}

(a) The internal particles in broken coal and rock were mainly caused by extrusion, deformation, and structural adjustment. In the case of broken coal and rock, the main processes were extrusion, deformation, and particle crushing. The permeability of the broken sample showed a decreasing trend. In addition, the permeability of the broken sample was significantly reduced after a loading and unloading cycle. The loading stage had a greater impact on the broken sample as compared to the unloading stage

(b) When the proportion of coal particles in the broken sample was $50 \%$, the irreversible permeability damage rate and the permeability damage rate of the sample presented the highest values. This result was bigger than that obtained for the broken samples 
containing a proportion of coal particles of 0.3 and 0.7. The irreversible permeability damage rate and permeability damage rate of the broken rock mass were greater than those of the broken coal mass. In relation to broken coal rock, when the proportion of rock particles was relatively large, the damage degree of the internal particles and the degree of change of the pore structure were significantly higher. When the proportion of coal and rock was the same, the degree of change presented the highest value

(c) The stress sensitivity coefficient curves of the five types of broken coal and rock masses were consistent. In addition, the stress sensitivity coefficient and effective stress can be fitted to the Darcy equation. The higher the number of rock particles inside the broken sample, the higher the sensitivity of the sample to effective stress and the greater the degree of change

\section{Abbreviations}

$\begin{array}{ll}n: & \text { Coal to rock volume ratio } \\ k: & \text { Dimensionless permeability } \\ \sigma_{\mathrm{e}}: & \text { Average effective stress } \\ K_{n}: & \text { Permeability in the subsequent stress point } \\ \sigma_{\mathrm{a}}: & \text { Axial pressure } \\ e: & \text { Crack opening } \\ P_{1}-P_{2}: & \text { Air pressure difference } \\ \mathrm{JRC}: & \text { The roughness coefficient } \\ K: & \text { Permeability } \\ Z: & \text { The root mean square } \\ Q: & \text { Gas flow rate } \\ D_{k_{1}}: & \text { The irreversible permeability damage rate } \\ \mu: & \text { The fluid viscosity coefficient } \\ D_{k_{2}}: & \text { The permeability damage rate } \\ L: & \text { Coal sample length } \\ A: & \text { Coal sample base area. }\end{array}$

\section{Data Availability}

The data obtained in the present research are available from the corresponding author upon request.

\section{Conflicts of Interest}

The authors declare that there are no conflicts of interest regarding the publication of this paper.

\section{Acknowledgments}

This research is supported by the National Natural Science Foundation of China (Grant Nos. 51704274 and 52174129), the Project of "Youth Elite Scientists Sponsorship Program by Cast" of China Association for Science and Technology (Grant No. 2017QNRC001), and the Jiangsu Province Scientific Research and Practice Innovation Project (Grant No. KYCX21_2390).

\section{References}

[1] Z. H. Cheng, Q. X. Qi, H. Y. Li, L. Zhang, and X. G. Liu, "Evolution of the super imposed mining induced stressfissure field under extracting of close distance coal seam group," Journal of China Coal Society, vol. 41, no. 2, pp. 367375, 2016.

[2] C. Zhang and L. Zhang, "Permeability characteristics of broken coal and rock under cyclic loading and unloading," Natural Resources Research, vol. 28, no. 3, pp. 1055-1069, 2019.

[3] J. A. Mccorquodale, A.-A. A. Hannoura, and M. Sam Nasser, "Hydraulic conductivity of rockfill," Journal of Hydraulic Research, vol. 16, no. 2, pp. 123-137, 1978.

[4] P. GN and P. Venkataraman, "P. Non-Darcy converging flow through coarse granular media," Journal of the Institution of Engineers (India): Civil Engineering Division, vol. 76, pp. 611, 1995.

[5] M. G. Qian, X. X. Miao, J. L. Xu, and S. G. Cao, "On scientized mining," Journal of Mining \& Safety Engineering, vol. 1, pp. 110, 2008.

[6] H. B. Shang, D. W. Jin, T. J. Zhang et al., "Permeability evolution of broken coal under triaxial stress," Journal of China Coal Society, vol. 44, no. 4, pp. 1066-1075, 2019.

[7] W. Wang, C. Zhang, S. X. Wu, S. Jia, and Y. S. Yang, "Experimental study on seepage characteristics of broken coal and rock samples in caving zone under cyclic loading and unloading," Journal of Mining Science and Technology, vol. 5, no. 4, pp. 374-381, 2020.

[8] M. G. Yu, J. K. Chao, T. X. Chu, F. Teng, and P. Li, "Experimental study on permeability parameter evolution of pressure-bear broken coal," Journal of China Coal Society, vol. 42, no. 4, pp. 916-922, 2017.

[9] C. Zhang, S. H. Tu, and L. Zhang, "Study of stress sensitivity of coal samples with different mining damage in overlying strata," Journal of China University of Mininge Technology, vol. 47 , no. 3, pp. 502-511, 2018.

[10] C. Zhang, Coupling Mechanism of Stress-Fracture-Flow in High Gas Coal Seam Group and Its Impact on Pressure Relief Extraction, [Ph.D. Thesis], China University of Mining and Technology, Xuzhou, 2017.

[11] L. Z. Wang, Z. Q. Chen, H. L. Kong, and H. D. Shen, "Experimental study of impact of loading history on permeability characteristics of broken coal with different grain size gradations," Rock and Soil Mechanics, vol. 34, no. 5, pp. 13251330, 2013.

[12] T. J. Zhang, M. K. Pang, W. Q. Peng, N. Liu, and Y. G. Huang, "Seepage stability of cemented and fractured coal rock mass under tri-axial stress," Journal of Mining \& Safety Engineering, vol. 36, no. 4, pp. 834-840, 2019.

[13] Y. Xue, J. Liu, P. G. Ranjith, X. Liang, and S. Wang, "Investigation of the influence of gas fracturing on fracturing characteristics of coal mass and gas extraction efficiency based on a multi-physical field model," Journal of Petroleum Science and Engineering, vol. 206, article 109018, 2021.

[14] Y. Xue, T. Teng, F. Dang, Z. Ma, S. Wang, and H. Xue, "Productivity analysis of fractured wells in reservoir of hydrogen and carbon based on dual-porosity medium model," International Journal of Hydrogen Energy, vol. 45, no. 39, pp. 20240-20249, 2020.

[15] L. Zhang, Z. W. Ye, M. Q. Huang, and C. Zhang, "Characteristics of bituminous coal permeability response to the pore pressure and effective shear stress in the Huaibei coalfield in 
China," Geofluids, vol. 2019, Article ID 5489051, 12 pages, 2019.

[16] J. Lin, T. Ren, Y. Cheng, J. Nemcik, and G. Wang, "Cyclic $\mathrm{N}_{2}$ injection for enhanced coal seam gas recovery: a laboratory study," Energy, vol. 188, article 116115, 2019.

[17] G. Lei, P. C. Dong, S. Yang, B. Wang, Z. S. Wu, and S. Y. Mo, "Study of stress-sensitivity of low-permeability reservoir based on arrangement of particles," Rock and Soil Mechanics, vol. 35, Supplement 1, pp. 209-214, 2014.

[18] H. Ahn, S. Kim, M. Lee, and S. Wang, "Migration and residual trapping of immiscible fluids during cyclic injection: pore-scale observation and quantitative analysis," Geofluids, vol. 2020, Article ID 4569208, 13 pages, 2020.

[19] L. Zhang, J. H. Li, J. H. Xue, C. Zhang, and X. Q. Fang, "Experimental studies on the changing characteristics of the gas flow capacity on bituminous coal in $\mathrm{CO}_{2}$-ECBM and $\mathrm{N}_{2}$-ECBM," Fuel, vol. 291, article 120115, 2021.

[20] G. Wang, S. B. Wang, H. X. Li, X. J. Qin, and S. P. Li, "Study on water phase seepage evolution model considering mesoscale characteristics of pore and fissure in coal," Chinese Journal of Rock Mechanics and Engineering, vol. 40, no. 8, pp. 15471558, 2021.

[21] Q. Zhao, Study on Fluid-Solid Coupling Flow Mechanism of Fracture, Chengdu Southwest Petroleum University, 2015.

[22] M. N. Testamanti and R. Rezaee, "Considerations for the acquisition and inversion of NMR $\mathrm{T}_{2}$ data in shales," Journal of Petroleum Science and Engineering, vol. 174, pp. 177-188, 2019.

[23] L. Zhang, S. Lu, C. Zhang, and S. Chen, "Effect of cyclic hot/cold shock treatment on the permeability characteristics of bituminous coal under different temperature gradients," Journal of Natural Gas Science and Engineering, vol. 75, article 103121, 2020.

[24] Z. P. Meng and Q. L. Hou, "Experimental research on stress sensitivity of coal reservoir and its influencing factors," Journal of China Coal Society, vol. 37, no. 3, pp. 430-437, 2012.

[25] L. Zhang, S. Chen, J. H. Xue, T. X. Ren, and C. Zhang, "Permeability of bituminous coal and its stress sensitivity under liquid nitrogen fracturing," Journal of Mining \& Safety Engineering, vol. 37, no. 2, pp. 401-408, 2020. 